variation in the molecular interchange in the blood, appear in the tissue either as glucose $2\left(\mathrm{C}_{2} \mathrm{H}_{6} \mathrm{O}\right) \mathrm{CO}_{2}$, or as lactic acid $2 \mathrm{C}_{3} \mathrm{H}_{6} \mathrm{O}_{3}$, which last we know does appear in muscle when the power of the coördinating centre is removed.

$$
\text { IN tTrer. }
$$$$
4 \mathrm{C}_{4} \mathrm{H}_{9} \mathrm{~N}_{3} \mathrm{O}_{2}
$$$$
\underset{\substack{\text { hydrated } \\ \text { into }}}{\text { Ur }}
$$

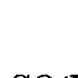

IN Tissue.
$\left.\mathrm{CO}\left(\mathrm{NH}_{2}\right) \mathrm{C}_{2} \mathrm{H}_{5} \mathrm{O}\right\}\{\mathrm{CN}$

The following substances, with others, would exist in the liver and tissue (urea and carbonic acid being eliminated as formed), according as the blood had a normal alkaline or abnormal reaction :-

TAble I. - Blood Normal.

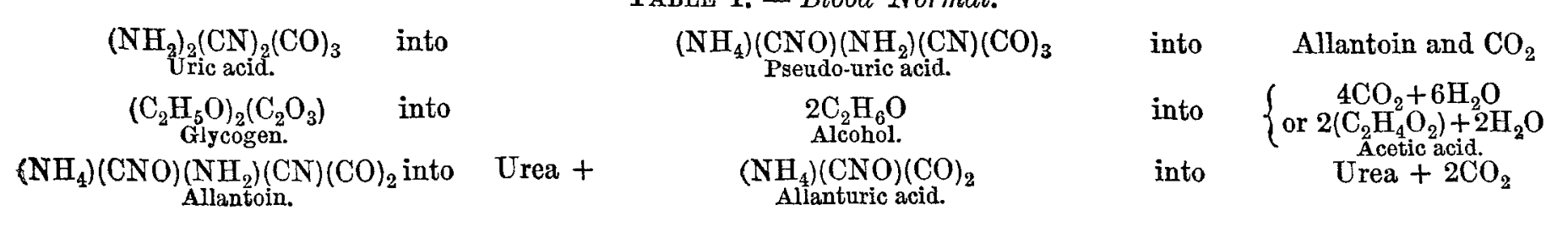

TABLE II. - Blood Abnormal.

$\begin{array}{ccc}\left(\mathrm{NH}_{2}\right)_{2}(\mathrm{CN})_{2}(\mathrm{CO})_{3} & \text { into } & \text { Urea }+ \\ \text { Uric acid. } & & \\ \left(\mathrm{C}_{2} \mathrm{H}_{5} \mathrm{O}\right)_{2}\left(\mathrm{C}_{2} \mathrm{O}_{3}\right) & \text { into } & \\ \text { Glycogen. } & & \\ \left(\mathrm{NH}_{2}\right)(\mathrm{CN}) \mathrm{C}_{3} \mathrm{O}_{4} & \text { into } & \text { Urea }+ \\ \text { Alloxan. } & & \end{array}$

Consequently, if the power of the coördinating centre is removed or impaired, we should have, as shown in Table 2, simultaneously in the liver, and as the last stage in the process, glycogen about to be transformed, and appear in the tissue as lactic acid or as glucose, and alloxan about to be split up into urea and mesoxalic acid; and to this point I shall refer when dealing with the action of remedies.

It would seem from these hypotheses that in a state of health glycogen and glucose are abnormal constituents of muscle, the liver glycogen appearing in the tissue as $2 \mathrm{C}_{2} \mathrm{H}_{6} \mathrm{O}$, to be at once transformed into $\mathrm{CO}_{2}$ and $\mathrm{H}_{2} \mathrm{O}$. But, if the controlling power is weakened, glycogen is transformed, and appears in the tissue as lactic acid or glucose, according to the extent to which that power is weakened, and according to the variation in the molecular change along the blood line; and these substances may also, from the same causes, appear in the blood itself. If lactic acid produces the same effect on the smaller arteries of the kidney as was seen in the experiments of Dr. Gaskell to be the effect on those of muscular tissue, and so (under certain conditions of the red blood-corpuscles to be presently referred to) act as a diuretic, the experiments of Claude Bernard seem to support very strongly the view I have here advanced as to the common origin of glucose and of lactic acid. "When we prick the mesial line in the floor of the fourth ventricle, in the centre of the space between the origins of the auditory and pneumogastric nerves we at the same time produce an exaggeration of the hepatic (saccharine) and of the renal secretions; if the puncture be effected a little higher, we very often only produce an augmentation in the quantity of the urine, which then frequently becomes charged with albuminous matters; while if the puncture be below the indicated point, the discharge of sugar alone is observed, and the urine remains turbid and scanty. .... As these two points are very near one another, it often happens that if the instrument enters obliquely they are simultaneously wounded, and the animal's urine not only becomes superabundant but saccharine." 9

9 Med. Chirur. Review, Jan. 1857, p. 42.

\section{ON RICKETS.}

By JAMES F. GOODHART, M.D., F.R.C.P., ASSISTANT-PHYSICIAN TO GUY'S HOSPITAL, AND TO THE EVELINA HOSPITAL FOR CHILDKEN. it was necessary to compress what $I$ had to say into the last five minutes of an unusually long sitting, and to this was added the knowledge that the opener of the debate had still to occupy more time with his reply. Such conditions were conducire more to vigour than to precision of statement; some things that I wished to say had to be omitted, and thers were too shortly put to make my full meaning in.
AT the discussion on Rickets at the Pathological Society
Lastly, though it is most probable that in health the various substances are oxidised in the tissues and not in the blood, yet where there are morbid changes and abnormal products appearing in the blood, if the energy of the red blood-corpuscles as carriers of oxygen from the lungs is not lessened it seems hardly possible that oxidation of oxidisable substances should not take place there. How else can the conversion of vegetable acids be explained, which, when administered internally, are eliminated as carbonates? In acute rheumatism it would seem probable, therefore, that there is increased heat or pyrexia, partly by increased oxida. tion in the tissue from the smaller arteries dilating, owing to the presence of lactic acid in the blood, and partly also by the oxidation of the lactic acid in the blood itself; and that from the increased oxidation in the tissue an excessive amount of uric acid is formed, which the liver is unable to act upon; it escapes into the blood unchanged, and is eliminated by the kidneys.

If the energy of the red blood-corpuscles was in any way diminished or inhibited, and there was no increased oxidation going on from lactic acid being present in the blood, but merely dilatation of the minute arteries, then if the vessels of the kidney were affected in the same way we should have simply increased flow of urine-diabetes insipidus. Again, in diabetes mellitus as there is no rise of temperature, and the glucose is not oxidised in the blood, is the energy or number of the red blood-corpuscles inhibited or modified? -and if the energy were unrestrained, would this give rise to hyperpyrexia? We know that during the progress of disease intercurrent with diabetes the sugar does sometimes disappear from the urine, but this may be only from the introduction of some zymotic element into the blood. nating chemical centre" presiding over the changes in the tissue and in the liver, and a variable energy in the action of the red blood-corpuscles, may express the pathological rela. tionship between hyperpyrexia, diabetes mellitus, acute rheumatism, and diabetes insipidus?

(To be concluded.)
Is it possible, then, that altered intensity of the "coördi-

telligible. But though obscurely stated, the points themselves are not unimportant, and considering that so few facts have been added to our knowledge, I venture to put on paper in a more detailed manner what I should have said elsewhere had time permitted me, and while attention is still directed to the subject.

My text is visceral rickets, if there is such a thing. Three propositions concerning this branch of the subject have been put forward at one time or another.

1. That the spleen and liver are not enlarged in ricketsthe seeming increase is due to displacement.

2. That the enlargement of the spleen and liver is as much a part of the disease as the changes in the bones-an opinion advanced by Sir Wm. Jenner and supported by Dr. Dickinson.

3. That the viscera are enlarged, but present no distinc- 
tive features, and that the increase in size is due to some cause antecedent to it, and the skeletal changes-an opinion attributed to Dr. Gee and reaffirmed by Dr. Hilton Fagge.

I shall confine myself mostly to the question of splenic enlargement, because I think the facts at hand concerning the liver are hardly sufficient to enable us to form a positive opinion whether it is or is not diseased in rickets. To take the three statements in order-

1. Is the spleen enlarged, or is it not?

It is certainly enlarged in some cases'of rickets- $-(a)$ by the unanswerable proof afforded by post-mortem examinations ; (b) I have notes of cases in which the spleen has occupied a third at least of the abdominal cavity during life, an amount of enlargement which puts the possibility of a mere dis. placement in such quite out of the question; and $(c)$ it is possible to separate during life those cases of rickets with splenic enlargement from those without it, almost withont physical examination, by means of the peculiar pallor which the splenic cases present.

No further evidence is wanting to demonstrate that an actual increase in the size of the spleen is, at any rate, an occasional fact in the history of rickets.

Having stated that there is post-portem proof of splenic enlargement in rickets, I will next state what is the change which, I conceive, such spleens to have undergone-a point upon which there has been some difference of opinion, even in the late discussion. I have examined four cases; and, to judge from them, the spleen is large and firm, with some slight thickenings of its capsule ; its section is homogeneous in appearance, from the paucity of the Malpighian corpuscles and the want of contrast which is usually afforded between them and the splenic pulp. Under the microscope the change is one of hyaline fibroid thickening of the septa and stroma at the expense of the pulp and Malpighian sheaths. I have described and figured this condition elsewhere, ${ }^{1}$ so that it is unnecessary to say more of it here.

From this it will be seen that $I$ am quite in accord with Dr. Dickinson, so far as the spleen is concerned, that the change is one of interstitial splenitis, if it be desirable to call it so, but perhaps better, of interstitial fibrosis, the new material being of a hyaline kind, and not necessarily, by any means, the outcome of an inflammatory state. I have not been able to detect any similar change in the liver; or, perhaps, to put this statement more guardedly, I have not been able to satisfy myself that this material exists in the rachitic liver in an abnormal quantity.

Sir Wm. Jenner alluded to some observations of his own, in which the spleen and liver in thin sections were found to be glue-like from the presence of a peculiar morbid deposit, appearances which he considered denoted something of an unusual kind, and he therefore takes exception to Dr. Dickinson's description of the change as one of interstitial fibrosis. But, if I may be allowed to say so, the observations of Sir Wm. Jenner are by no means irreconcilable with those of Dr. Dickinson. It will be allowed that the glue-like change must have been exceptionally extreme, and it is well known that this fibrous material, or hyaline fibroid, when it rises to an extreme degree, presents just such a gristly, cartilaginous, and in thin slices, glue-like appearance, as was noticed by Sir Wm. Jenner; and so far from any antagonism, we have, indeed, some remarkable facts in corroboration of theassertion that the disease is one of thickening of the stroma of certain organs. The orginal term-albuminoid-applied to this material is not by any means a bad one as applied to the morbid material itself; it is objectionable chiefly in that it has been taken to indicate something peculiar to the morbid deposit of rickets-a something not found in other diseaseswhereas the material does not differ from that found in several other states, or, to speak more precisely, from the morbid material found in the spleen in chronic enlargement, from ague, and many other conditions.

When I come to the next question, What is the relation between splenic enlargement and rickets? I am no longer able to keep company with Dr. Dickinson, as I am unable to support his contention that the visceral enlargement is as much a part of the disease as are the skeletal changes. I am mostly influenced in thinking otherwise by finding that the splenic enlargement, in my experience, occurs in but a small proportion of cases of rachitis, and that when it does occur it is by no means, in the worst cases. I am unable to say what number of cases of rickets have come under my notice, but, as is patent, they form a staple commodity in

I New Sydenham Society: Atlas of Pathology, Fasciculus 2. out-patient practice, and it is certainly a very moderate computation to say that in the last seven years $I$ have seen 800 to 1000 cases, and it has always been my habit to examine for splenic enlargement, and all such eases have been carefully recorded. Referring to these notes I find fifty-three cases of splenic enlargement of all sorts. They are grouped as follows :-

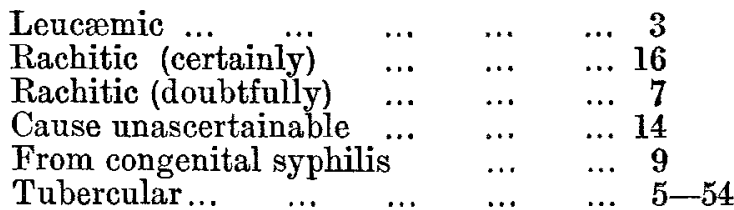

One of these cases being both syphilitic and rachitic has been included under both heads, explaining the fifty-four total. Now, considering the difficulty which exists in distinguishing slight degrees of rickets, we may include the doubtfully rickety enlargements as rickets, and we have then twenty-three cases; we might even do more, and include those cases in which the enlargement was due to no very obvious cause-a matter of fourteen more, or thirtyseven all told. And they would still-although rachitic enlargements form the greater part of all the splenic casesform so small a proportion of all the cases of rickets, as can hardly be said to indicate that the enlargement is as much a part of the disease as the changes in the bones. I have called no spleen enlarged which was not certainly palpable below the ribs, or if the chest was sufficiently distorted to explain its altered position.

It does not seem, therefore, that the swelling of the spleen can be in any sense essential to rickets, since it occurs so seldom; and I am disposed to agree with Dr. Gee and Dr. Hilton Fagge that when it occurs it is due to some cause which antedates both it and the bone enlargement.

It may, however, be said that this argument is much weakened by the fact of congenital syphilis, as shown in my own table. Congenital syphilis is very common in the outpatient room; and if we were to enumerate all the cases and estimate the proportion in which enlargement of the spleen occurs, it would be but a small one-smaller, I think, than that of enlargement of the spleen to rickets. I have notes of nine cases only. But though such a small percentage of all the cases, it is not contested that the splenic enlargement of syphilis is an integral part of the disease, as much as the other signs of the malady. This is all true; but then, on the other hand, there is this difference-the spleen in congenital syphilis, and the liver also, are known to present certain definite cell proliferations, which are similar to those in other parts, and similar to those of syphilis in the adult. This is not so in rickets. The change in the one may be said to be specific, in the other "indifferent."

The liver of rickets appears to be, from my notes, but seldom enlarged, and when it is the increase is, as $\mathrm{Dr}$. Dickinson has already stated, inconsiderable.

Passing now to the blood and its condition in rickets, I have wondered that no one has hitherto drawn attention to it in this discussion until our President alluded to the absence of observations on the subject. I know not whether Mr. Hutchinson had in his mind a chemical or microscopical examination, or both. Both would be instructive, but a chemical examination of rachitic blood presents difficulties of achievement which I have not surmounted, and I can only speak of microscopical work. Some years ago I examined the blood of many rachitic children; the notes of these were scattered, and have unfortunately been mislaid, but I well remember that in many of them its condition was a very peculiar one, though it was not always the same. In some there was simple deficiency of corpuscles, in others deficiency of colouring matter; but in most these points were not so noticeable as the remarkable variety which the size of the red corpuscles exhibited. There were three, four, and five different sizes of red corpuscles, these going with a quantity of free granules; beaded strings and dumb-bell aggregations, such as have always been held to be morbid, but the exact significance of which is still doubtful. I have lately, for the purposes of this discussion, turned my attention again to this subject, and verified my former observations, though only in a few cases.

Whatever the significance of such changes may be it cannot be disputed that they may be of considerable importance, and they are in accord, I think, with the view expressed so clearly by $\mathrm{Mr}$. Hutchinson, that rickets is a diet disease. I am quite in accord with such an hypothesis. Nor 
can I see any difficulties in the way of accepting it provisionally, except that it appears to be difficult to prove its truth. Children are either fed badly or assimilate badly; bad blood is formed, and bad bone follows. The microscopical appearances of the blood are such as to suggest both immaturity and poverty. These are conditions, no doubt, which might in part, according to present physiological doctrine, be due to an abnormal bone development. But, on the other hand, there is a certain amount of evidence, perhaps I ought to say a consensus of opinion rather than evidence, in favour of rickets being produced by bad feeding. Bad feeding or faulty assimilation must act primarily upon the blood, but not necessarily by producing always a constant deficiency of one particular element or excess of others. A general lack all round would, it seems to me, be the alteration which would best supply the conditions which I conceive to be necessary for the production of rickets. But this brings me to a departure from facts, to which I have hitherto attempted to keep myself, to enter upon a somewhat speculative subject-the relation between the cartilaginous changes and the spanæmia. And, first of all, I would dwell especially upon this, that the histology of rickets points to improper development more than to disease. Clinically, of course, rickets is a disease, but pathologically it is not so much disease as arrest or perversion of the developmental process, and I would venture to make this criticism upon the suggestion that has been made, that rickets mollities ossium and senile fragilitas ossium are similar processes, differing only in the age of the patient that whereas rickets is a perverted development, those other states are degenerations of formed material, and one of them, senile fragilitas ossium, and perhaps the fragilitas essium of mental incapacity, has some ill-defined relationship to cancer which we as yet know little of. Though all of these have certain striking features of resemblance, such as distortion of the bones, yet in their essence they are far asunder, and there is nothing in the softening bone of old ege, that I can see, at all like the growth of cartilage that occurs in childhood in place of the normal growth of bone. It is a hazardous thing to attempt to say why or how any process takes place in the animal economy; but I cannot help suggesting that instead of considering rickets to be a disease we should look upon it as more a product of cultivation-a process allied to that which takes place when a gardener by particular soil essays to cultivate special parts of plants at the expense of the rest of the organism. Sup. posing we attempt to cultivate some flower or fern under conditions foreign to its habit, one of two things happensunless it be so hardy that its range of accommodation is a wide one-in the process of acclimatisation it becomes starved, and dwindles, and dies; or certain abnormalities crop up which it may or may not be to our interest to try and perpetuate. And should we replace the dwarfed organism under natural conditions it speedily reverts to the old type. Is it not thus with the infant? An attempt is made to acclimatise it to conditions unnatural to its development; its juices suffer in the process, and in most cases the result is slow starvation and death. But in still a large number of cases this extreme is averted, and some of the parts become, as it were, naturalised. The lower, or least specialised, tissues stand the ordeal best; the highly specialised waste. Hence fat and connective tissue and cartilage seem to have it all their own way; muscle and bone languish. Put the child again under natural conditions, and in the great majority of cases the tissues revert to their normal habit, and the rachitis disappears completely. I take this to be proved by the fact that any thing approaching to acute rickets, or, indeed, rickets of any sort, save its effects, is very uncommon after the age of six or eight. Have we any parallel case of a disease so severe as rickets, to judge from its distribution in the body, and affecting structures so important to young life as the bones, invariably getting well, if treated properly? I think not.

I would further remark that in cartilage we have to do with a peculiar tissue. It lives mostly by imbibition, and in one sense it is a coarse feeder, not very particular about quality so long as it is supplied with the requisite quantity. Witness the madder staining which can be practised upon it; the urate of soda it will tolerate with comparatively little reaction. It would seem to be more important for its well-being that it should have fluid than solids, as may readily be seen by the rapidity with which it shrinks to a mere relic when exposed to the atmosphere, and will regain its natural appearance by simply soaking in water. I can readily understand that material such as this will tolerate grave alterations in the fluids, and yet continue to thrire in some sense, nay, even to overgrow in the dropsical manner of the rachitic overgrowth, while the muscles are pale and tender from the badness of the supplies, and while all other parts are stunted and poor.

The changes in the viscera are not inconsistent with this view. An altered blood means for the tissues altered blood pressure, and this again implies considerable disturbance to the circulation in various localities with consequent changes in the tissues outside-congestion, œdema, \&c., are the natural consequences. And, if we further remember the close re lationship which exists between blood changes and splenic perhaps also hepatic, enlargement, there is no lack of material to explain the occasional occurrence of swelling of these viscera in rickets.

Nor do I think that such experiments as those given to us by Dr. Baxter tell against what I have here put forward. For although conducted, as they would certainly be by so shrewd and cautious an observer, with the greatest precision attainable, they are, they cannot be otherwise than, rough handed, when compared with the slow process of modification which goes on in the fluids of the infant under the many modes of artificial feeding adopted in this country, and pro. tected as the system is in a measure by the obvious fact that what does not please - that is, is not suitable to, an infant's stomach-will be rejected. I'do not doubt that an infant's stomach has, so to speak, a blind eye, but I do doubt whether many of the harmful compounds administered to it find this out, and enter the circulating fluids. And for this reason, because I believe it to be almost, if not quite, impos. sible so to direct the means sufficiently insidiously and persistently to the end aimed at-to be impossible, in fact, to perform any experiment which shall fulfil the required con. ditions - I dissent altogether from the doctrine of $\mathrm{my} \mathrm{col}$. league Mr. Lucas, that rickets can be induced with cer tainty by artificial feeding. The experiment is performed for us unconsciouslylin hundreds of cases by mothers with their children, and with a like result to that of Dr. Baxter with his puppies, the botanist with his ferns, of starvation, wasting, and death. But rickets can only be produced by a very slow process of careful cultivation, and provided that the gastric apparatus can be made to work subserviently to such an end. I see no reason with regard to animals why we should expect to produce rickets at all. Is not the rickets of animals expressed in the light porous periostitis-like bone which is to be found in most museums as a common disease of the lower animals.

I can only allude to other points very shortly. And, first as to foetal rickets. It appears to be assumed that if once foetal rickets is proved to have an existence the diet disease hypo thesis is no longer tenable. But does this follow? Why should the fotus be exempted altogether from diet diseases It obtains its food, it is true, already assimilated as blood but if a carefully adjusted and gradually adapted badness of blood be the cause of rickets, such a cause must surely operate sometimes in the foetus. I would rather hold to the opposite opinion - that, if it can be shown that foetal rickets has not even an occasional existence, a strong blow is thereby given to the diet disease hypothesis.

The next question I would ask is this, Is rickets only to be produced by one cause or set of conditions? I ask this because it seems again to be assumed that if the condition can be shown to be associated with cretinism it is no longer rickets. I am not prepared to admit this. I have elsewhere attempted to show ${ }^{2}$ that arrested development of the brain is a condition which favours excessive growth of the least specialised tissues, connective tissue (subcutaneous) and fat more particularly, but possibly cartilage also. From what I have seen of the cretin condition, particularly in a specimen lately presented to the College of Surgeons by Dr. Hermann, it seems to be an exaggerated rickets. The bones are all ends. The cartilaginous ends are exceed. ingly large ; the shafts unusually small. Is it not possible that this may prove to be a similar condition to that which we call rickets, though owning an entirely distinct origin?

The strongest argument against the view here taken of the nature of rickets may, I think, be derived from the fact thtat the disease is so little prevalent in other countries that it has received the name of the English disease ; yet I find it difficult to suppose, as does Dr. Baxter, that artificia feeding is so very different, in the United States for example,

2 On Sporadic Cretinism and Myxœdema (Med. Times and Gaz., 1880) 
from what it is here. I am not prepared to combat fully an objection of this kind at the present time, but I may just remind the reader that it has been one of my objects in the present paper to show that artificial feeding can only produce rickets under certain conditions, which may well be absent either in whole or part in other countries.

Weymouth-street, $W$.

\section{THE SIMULATION OF SOMNAMBULISM.}

\section{By CHAKLES RICHET, M.D. PARIS.}

(Concluded from p.9.)

ATALGESIA and anæsthesia are very often exhibited by somnambulists. These two phenomena are constant, or nearly so. It is now the fashion to say that the anæsthesia is due to simulation. Certainly, in considering the matter in a general way, insensibility may be feigned. But how many persons are there who would have the courage to bear without serious reason pricks on the face, on the nostrils, or hands; to allow their hair to be plucked out, and the conjunctiva, the nose, and the ears to be tickled; to have pins thrust into the arms; to drink nauseous liquids; to breathe with delight ammonia or sulphurous acid? Such are the tortures they would endure for the sole pleasure of duping the simple physician, who looks curiously on and takes notes. Nearly all somnambulists behave thus. They oppose no resistance to every test; they do not push them away, nor tremble, remaining impassive and vacant, braving without moving a muscle tests as disinterested as they are painful. Must we suppose that they exhibit heroism (and a very misplaced heroism) or anæsthesia?

I could multiply examples to prove how absurd is the hypothesis of simulation. Thus, nothing but the fact of being able to vomit at will indicates, indeed, that there is a psychical state different from the normal. Who is there who could vomit because one said to him, "What a bad smell!" It is, however, a constant phenomenon with the somnambulised; and to provoke the vomiting there is no need of a more complicated method. A somnambulist weeps when told to weep, sheds a flood of tears, and loudly sobs. Can we believe that it is easy to weep at will? Make the experiment on oneself, and see how impossible it is. Amicus noster quidem quem ad somnitationem facile suscitamamus, si de libidinosis rebus loquor, statim it erectionem. Si jubemus ut mingat, mingit; et restem foedat.

I recently witnessed an accident which might have been very grave, but which fortunately had no serious consequence. It was in the case of a young woman who will be frequently referred to in the course of this article, and who is an excellent magnetic subject. Wishing to excite fright in her. I said to her, "See, I take your arm, and I cut it. Look at the blood flowing." Immediately, without a cry or a gesture, she fell flat down on the ground, as if dead. In fact, life had ceased temporarily. The heart no longer beat, there was no respiratory movement; this state lasted for about half a minute-a century of anguish for me-then a deep respiration told of the return of vital phenomena. Perhaps it will be said, this syncope was only a clever piece of acting? However, at the risk of being thought to be very simple, I should not wish to try this experiment again at any price.

We may then, it seems, if not find an absolute or irrefutable proof, at least accumulate very convincing proofs to demonstrate that there is a somnambulistic condition. Let us now examine the objections opposed to it. The following are, if I am not mistaken, the chief :-

First objection. - The phenomena of somnambulism are incompatible with the facts of science. It is impossible to admit the "pass" can produce sleep, that a fluid escapes from the body at the will of the magnetiser, that thought is transmitted without an external manifestation, that vision is performed by the epigastrium, audition by the palm of the hand, and perception of taste by the forehead. It is easy to make answer : Somnambulism-this neurosis, whose causes and nature are still so mysterious-has nothing to do with the explanations attempted to account for it by charlatans. It is not a question of declining to refute their more or less interested vagaries, but of studying and verifying what has been seen by serious savants worthy of respect. All those who, instead of applying themselves to prove the inanity of the miracles performed by the somnambulised, have tried to see for themselves, have soon been convinced that by the influence of "passes," or by the "fixed gaze," there is produced a special neurosis, with well determined characteristics. It is easy to deny such or such grotesque tales, but what will they prove except that there are dupes and rogues mixed up in this problem of pathological physiology? It would seem, in view of so many wide. spread errors, that a number of truths must be found mingled with them. If it were all phantasmagory or simulation not only would magnetism not have been established, but it would not have been promulgated, and would have disappeared without leaving a trace behind. Error can only triumph by reason of the truth it enshrines.

Besides, we have not such perfect and precise notions on the nature and functions of the nervous system that we can deny the possibility of such or such a phenomenon. The experimental method should always guide us, and $\dot{\alpha}$ priori denials ought, like a priori affirmations, to be banished from scientific discussions. In truth, as regards somnambulism, the denials have always been $\dot{a}$ priori. I do not believe that an experimenter, supported by a sufficient number of facts, has come to the conclusion that somnambulism is not a fact. The denial has to be supported by reasoning, and not by experiment. No one yet, to my knowledge, has been able to say, "I have tried to hypnotise four persons, at different times, by employing the usual pro. cedure, and I have obtained no result." So far, people have been contented to smile, and to say, "It is impossible." Such a refutation seems to me insufficient.

Second objection.-Everything observed is inconstant, irregular, mobile. ${ }^{1}$ No fixed rule, the phenomena observed varying with every observer, and with each subject. What is predicted is not produced, and what is not predicted is produced. This objection is based on a real fact. Indeed, the first time that an individual is hypnotised, she finds herself in a special condition, which requires a real education. According as the experimenter desires to provoke this or that phenomenon, he will be able to direct the attention of the subject to it, and to act so that this phenomenon is produced. That simply means that will, habit, and education play an important part in the manifestations of the somnambulic neurosis. But this vague and unconscious influence cannot be regarded as simulation. When a lunatic reasons, reflects, meditates, he often shows evidence of much logic. Will it be said that he is not mad? Only people who know nothing of medicine would think so. In fact, a lunatic and a somnambulist reason, reflect, meditate, and it would be absurd therefore to conclude that they are simulating.

There are often seen certain strange psychological phenomena which it is necessary to know. Some hypnotised subjects regard their hallucinations as fictions, and say that what they see before them, with forms apparently real, is not reality. This is observed in dreaming, and also in insanity. We often dream of monsters so strange and visions so absurd that we cannot believe them. There occurs also a sort of doubling of consciousness; we dream and we know that we are dealing with a dream, and we make great efforts to drive away the vision which oppresses us. So do those who have hallucinations hear voices which they very well know to be subjective. So also certain somnambulists are conscious of their state, and thus a curious antagonism is set up in them. Their imagination shows them the real form of things, and their intelligence understands their absurdity. That is why they often exhibit contradictions, which, to a superficial observer, would seem to reveal simulation. The fact was very striking with a patient at Beaujon, quite a young girl, whom I hypnotised on several occasions with the greatest facility. I told her that I was going to perform a painful operation on her-amputation of the arm, for ex-

I In an article in The Times, where a paper I contributed to the Revue des Deux Mondes, on "Demoniacs, Past and Present," is analysed, Revue des Deux Mondes, on "Demoniacs, Past and Present," is analysed, to describe the changing and fugitive phenomena of hysteria. As much. to describe the changing and fugitive phenomena of hysteria. As much, said the critic, might one try to fir on a photographic plate the mobile surface of tho ocean. Now, this observation, which appears to me to be of slight foundation, and little justified by fact, is joined by another reproach quite as singular; it is that things are spoken of which we ought to be silent about; that we provoke, by the description of hysteria, attacks of this disease; that we contribute, in a word, not to the knowledge but to the extension of the disease. Surely this is scientific prudery? 